\title{
BMJ Open Quality Nudging healthcare professionals to improve treatment of COVID-19: a narrative review
}

\author{
Andreas Vilhelmsson (D) , ${ }^{1,2}$ Anita Sant'Anna, ${ }^{3}$ Axel Wolf ${ }^{1,4}$
}

To cite: Vilhelmsson $A$, Sant'Anna A, Wolf A. Nudging healthcare professionals to improve treatment of COVID-19: a narrative review. BMJ Open Quality 2021;10:e001522. doi:10.1136/ bmjoq-2021-001522

- Additional supplemental material is published online only. To view, please visit the journal online (http://dx.doi.org/10. 1136/bmjoq-2021-001522).

Received 10 April 2021 Accepted 25 November 2021

Check for updates

(c) Author(s) (or their employer(s)) 2021. Re-use permitted under CC BY-NC. No commercial re-use. See rights and permissions. Published by BMJ.

${ }^{1}$ Centre for Person-Centred Care (GPCC), University of Gothenburg, Gothenburg, Sweden

${ }^{2}$ Occupational and Environmental Medicine, Lund University Faculty of Medicine, Lund, Sweden

${ }^{3}$ Viniam Consulting, Halmstad, Sweden

${ }^{4}$ Department of Anaesthesiology and Intensive Care Medicine,

Sahlgrenska University Hospital, Gothenburg, Sweden

Correspondence to Dr Andreas Vilhelmsson; andreas.vilhelmsson@gu.se

\section{INTRODUCTION}

The COVID-19 pandemic has placed unprecedented stress on healthcare systems worldwide and disrupted routine care. Healthcare professionals (HCPs) have had to quickly improvise and adapt to cope with a novel deadly virus with uncertain treatment options, lack of evidence, and a shortage of medical supply and personal protective equipment.

In an ideal world, clinicians would base their decisions on scientific evidence and best practices. In practice, however, behavioural science shows that decisions are affected by emotional and cognitive biases, especially under stress. ${ }^{1}{ }^{2}$ Understanding the behavioural nature of decision-making is essential for designing processes that mitigate risks and improve the quality of care. This is particularly important because of the fast-paced developments characterising the COVID-19 pandemic.

One effective strategy in improving decision-making is nudging: subtle changes to the design of the environment or framing choices without restrictions to encourage a given behaviour. ${ }^{3}$ These strategies are often easy to scale and implement at a low cost, making nudging a practical approach to behaviour change. ${ }^{4}$ Nudging interventions have been widely effective, ${ }^{5-15}$ but often patient directed, and less attention has been given to the use of behavioural insights to support HCPs in making appropriate medical decisions.

In this review, we synthesise the available literature on how nudging techniques can be used to affect the behaviour of HCPs in clinical settings in order to see if these can be useful in the prevention and treatment of COVID-19. The results are intended to guide and inspire quick implementation of cost-effective solutions that can improve the quality of care.

Our objective was to identify interventions using nudge theory ${ }^{3}$ to affect the behaviour of HCPs in clinical settings, focusing on target groups, nudging techniques, delivery systems and empirical evidence.

\section{METHODS}

We conducted a narrative review to explore the role of nudging in supporting HCPs in the prevention and treatment of COVID-19.

Studies eligible for inclusion were: (1) interventions conducted in a clinical setting targeting healthcare personnel, (2) behavioural interventions using the term nudging, (3) randomised controlled trials, quasi-experimental or longitudinal (beforeafter) studies, (4) original research articles published in English and in peer-reviewed journals between 2010 and 2020.

Articles were searched by an information specialist at the university library on two electronic databases: PubMed and PsycINFO. We searched the term 'nudging', 'nudges', or 'nudge' in the titles or abstracts of articles published from January 2010 to December 2020. Two of the authors performed individual blinded screening of titles and abstracts from the search using the Rayyan QCRI systematic review tool. ${ }^{16}$ Studies were selected in three phases: (a) removing duplicates, (b) screening titles and abstracts, and (c) screening full-text articles.

Articles that described an intervention to change the behaviour of HCPs in a clinical setting and deemed relevant to COVID-19 were included. Reviews, opinion letters, editorials, and publications that were not published in English were excluded and nudging interventions not relevant to the treatment of COVID-19 (The table is in the repository Zenodo. https://doi.org/10. 5281/zenodo.5545926).

The blind was then lifted, and any disagreements between authors were discussed with a third author until a consensus was reached.

The included articles were then reviewed to extract key information about each 
intervention, including purpose, target behaviour, measured outcomes, key findings, nudging strategies used and their theoretical underpinnings. The characteristics of the nudging strategies that would allow for systematic grouping were identified. Several grouping approaches were discussed until the most appropriate grouping was selected. The studies were categorised and characterised using descriptive analysis.

Nudging is often referenced to two modes of thinking: the automatic system (system 1) and the reflective system (system 2) ${ }^{3}{ }^{317}$ However, the underlying behavioural strategies that give rise to different interventions are not always described or easy to characterise. Therefore, we categorised the nudging strategies according to two practical dimensions:

- Synchronous versus asynchronous: an intervention strategy is synchronous if its delivery coincides with the decision or behaviour it intends to affect, while an asynchronous strategy can be performed anytime. For example, providing alternative options when a clinician is prescribing antibiotics in the electronic system is a synchronous strategy: alternative options (nudge) are presented when the prescription (target behaviour) is taking place. A poster providing information on sound antibiotic prescribing is an asynchronous strategy not connected to a specific prescription.

- Active versus passive: an active strategy cannot be completed without action from the targeted clinician, while a passive strategy does not require any action. For example, requesting written justifications for an antibiotic prescription to complete the order is active strategy: the prescription (target behaviour) cannot be completed without justification (nudge), while changing the default prescription is a passive strategy.

\section{RESULTS}

The database search yielded 1436 articles (figure 1); 36 duplicates and additional 1352 articles that did not fulfil the inclusion criteria were excluded. Of the 48 articles included for full-text review, 28 were excluded because they were not relevant to COVID-19, resulting in 20 articles included in the analysis.

\section{Summary of the included studies}

Table 1 summarises the characteristics of the included studies. Online supplemental table $\mathrm{S} 1$ gives a more detailed view of the different interventions.

Four different focus areas relevant to COVID-19 were identified: ventilation, hand hygiene, vaccination and antibiotics (online supplemental table S1 for a more detailed view, and S2 table https://doi.org/10.5281/ zenodo.5545926 for full view). Four studies related to ventilation of intubated patients, ${ }^{18-21}$ five targeted hand hygiene measures, ${ }^{22-26}$ six focused on increasing vaccination rates ${ }^{27-32}$ and five focused on encouraging judicious antibiotic prescription. ${ }^{33-37}$

Out of the 20 studies included for analysis, seven employed more than one medium of intervention, and
13 employed only one. While seven studies delivered the intervention via electronic health records (EHRs) or electronic prescription ordering systems, nine used communication technologies such as email, text messages or traditional letters. Six studies altered the physical environment by using posters, lights or aromatisation, two made modifications to the ventilation machines and two introduced electronic dashboards. Seventeen of the 20 articles had a statistically significant positive result (online supplemental table S1). Of the three that failed, two ${ }^{24} 29$ delivered the nudge through email and one through letter. ${ }^{30}$

Overall, 28 different nudging strategies were identified, including accountable justifications, active choices, alerts and reminders, default settings, environmental cueing, feedback, peer comparison, goal setting, information transparency, suggested alternatives and education (online supplemental table S1). There was no standard nomenclature across articles, and many of the articles did not discuss the underlying behavioural theories that gave rise to the nudging intervention.

The authors characterised each of the identified nudging strategies as active, passive, synchronous or asynchronous (figure 2). Seven studies used a combination of several intervention strategies. While this increases the possibility of an effective intervention, it also makes it difficult to determine exactly which strategies make an intervention successful.

\section{Description of the nudging content and strategies Improving care for mechanically ventilated patients}

All four nudging interventions had significant positive results. Two studies ${ }^{19} 20$ achieved a significant improvement by changing the default ventilator settings to comply with evidence. O'Reilly-Shah $e t a l^{20}$ complemented their intervention with personal emails to clinicians, summarising compliance metrics compared with department goals. These passive and asynchronous strategies do not require any action on the part of the clinician and can be performed anytime.

Anderson $e t a l^{21}$ reduced the duration of mechanical ventilation (MV) and intensive care unit (ICU) length of stay by implementing an electronic dashboard and alert system to promote sedation minimisation and ventilator liberation. The intervention consisted of: (1) a web-based dashboard with real-time data on spontaneous breathing trial readiness, sedation depth, sedative infusions, and nudges to wean sedation and ventilator support; and (2) text-message alerts once patients met the criteria for spontaneous breathing and spontaneous awakening trials. A real-time dashboard was also implemented to visualise which patients were receiving appropriate low tidal volume (TVe) ${ }^{19}$ These active strategies prompt clinicians to make conscious decisions at a critical moment.

Another intervention beneficial to MV patients is the use of chlorhexidine mouthwash, which reduces the rate of ventilator-associated pneumonia (VAP) in critically ill patients. An intervention was designed with chlorhexidine mouthwash as a default prescription to the electronic 


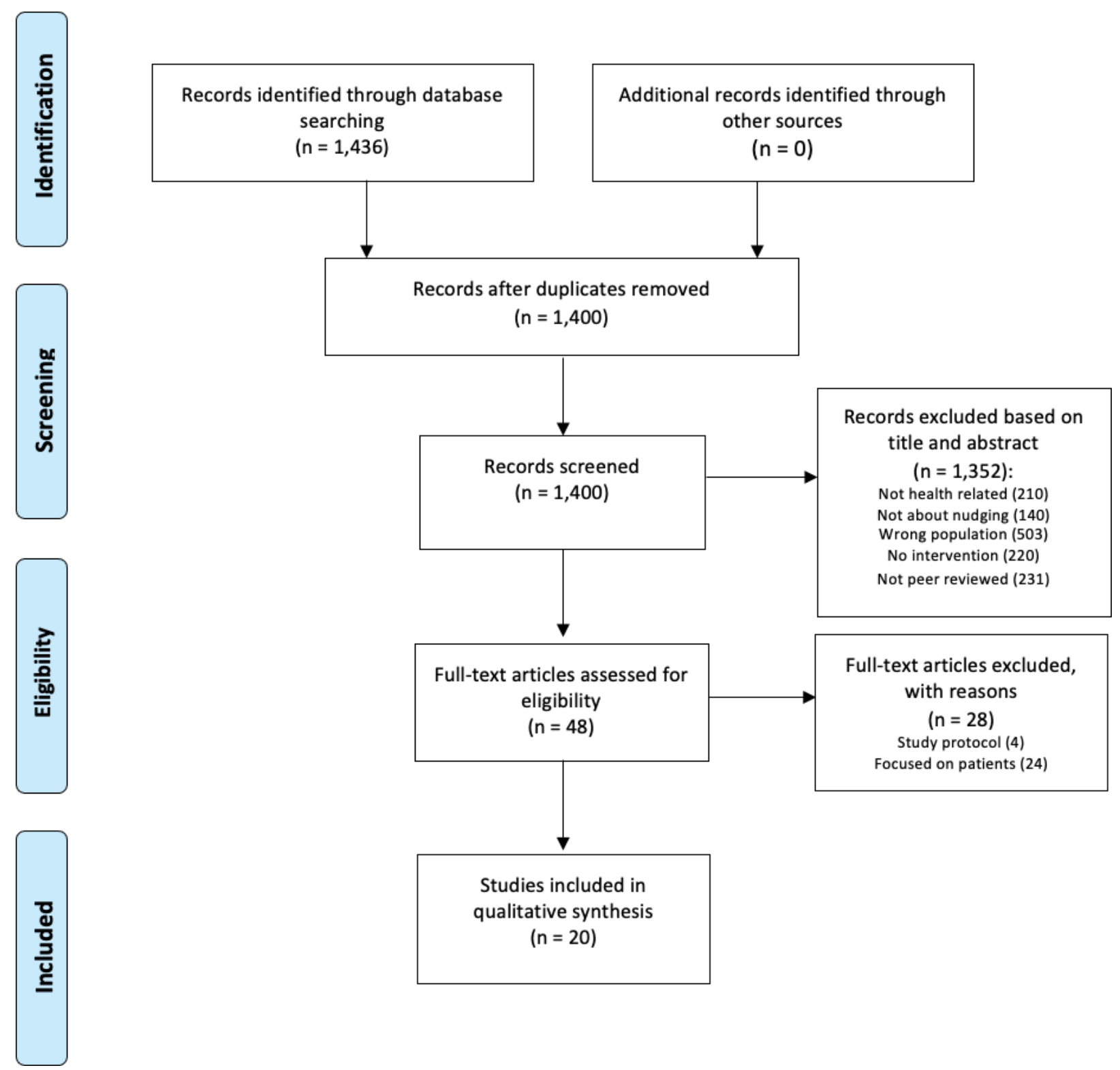

Figure 1 Flow diagram of publication selection process.

prescribing template, leading to a significant increase in its prescription. ${ }^{18}$ Although ordering a prescription is a conscious decision, including default orders is a passive strategy that reduces the cognitive burden. No active action is required unless the clinician has a strong reason to remove the default order.

\section{Improving hand hygiene in the hospital or clinic}

Four of the five studies showed a significant positive result. Posters with carefully crafted messages and hand washing pictures effectively increased the use of hand sanitisers. ${ }^{22}$ One of the messages appealed to social norms-'Half of all healthcare workers performed well in hand hygiene. Which category do you belong?'-and the other to loss aversion- $\mathrm{a}$ ' $40 \%$ increase in hand hygiene, and a $40 \%$ decrease in healthcare-associated infections'. Pictures of eyes were placed above a hand gel dispenser to introduce a perception of being watched ${ }^{23}$ and 'fresh citrus' fragrances were dispersed into the environment to achieve a significant positive effect on hand hygiene. ${ }^{23} 25$ Both the visual and olfactory cues described above were passive and asynchronous.

Iversen $e t a t^{26}$ used smart sensors and light displays placed on alcohol gel dispensers as a more active strategy. The light display switched between random lights (cue) and green smileys after hand hygiene (reward) to reinforce the desired behaviour. The target action of using the alcohol gel dispenser produced a synchronous reward, creating a positive association. The authors complemented their environmental nudge with performance feedback, highlighting hand hygiene compliance in different rooms as well as before and after patient contact, individually and compared with colleagues.

Despite not achieving a significant positive result, Kwok et $a t^{24}$ showed that social cohesion-colleagues reminding 
Table 1 Characteristics of the articles included in the review

\begin{tabular}{|c|c|c|}
\hline Reference & Nudging objective and target & Implementation details \\
\hline $\begin{array}{l}\text { Bourdeaux et } \\
\text { al }{ }^{18}\end{array}$ & $\begin{array}{l}\text { Increase prescription of a } \\
\text { mouthwash and reduce the } \\
\text { prescription of an intravenous fluid } \\
\text { among ICU HCPs. }\end{array}$ & $\begin{array}{l}\text { Chlorhexidine mouthwash was added as } \\
\text { a default prescription to the prescribing } \\
\text { template and hydroxyethyl starch was } \\
\text { removed from the prescribing template. }\end{array}$ \\
\hline
\end{tabular}

Bourdeaux et Increase compliance from ICU HCPs Default ventilator settings were adjusted $a l^{19} \quad$ with TVe ventilation.

to comply with low TVe targets and a large dashboard was deployed displaying TVe with alerts when TVe was excessive.

$\begin{array}{ll}\begin{array}{l}\text { O'Reilly-Shah } \\ \text { et } a l^{20}\end{array} & \begin{array}{l}\text { Improve compliance from hospital } \\ \text { HCPs with LPV strategies. }\end{array} \\ \begin{array}{ll}\text { Anderson et } \\ \text { al }^{21}\end{array} & \begin{array}{l}\text { To promote sedation minimisation } \\ \text { and ventilator liberation among ICU } \\ \text { HCPs. }\end{array}\end{array}$

$\begin{array}{ll}\text { Caris et } \mathrm{al}^{22} & \begin{array}{l}\text { Increase the use of alcohol-based } \\ \text { hand rub among ICU physicians and } \\ \text { nurses. }\end{array}\end{array}$

King et $a^{23} \quad$ Influence HHC among ICU HCPs

$\begin{array}{ll}\text { Kwok et }^{24} & \text { Improve HHC among hospital ward } \\ \text { HCPs. }\end{array}$

Dashboard with compliance metrics were emailed to providers. Additionally, default setting on anaesthesia machines for TVe was decreased.

\section{Findings}

Patients prescribed chlorhexidine increased while patients prescribed hydroxyethyl starch decreased.

In the dashboard intervention, TVe fell more quickly and by a greater amount.

Dashboards and modification of default ventilator settings improved provider compliance with LPV strategies.

A web-based dashboard with real-time data Patients were more likely to be and text-message alerts once patients met extubated and more likely to be criteria for a spontaneous breathing trial and spontaneous awakening trial. discharged from the ICU at any point.

Hand hygiene posters were displayed to assess their effect on the use of alcoholbased hand rub, measured with electronic dispensers.

A clean, citrus smell was released in the air and pictures of male or female eyes were placed above a hand gel dispenser to introduce a perception of being watched.

Nurse unit managers were provided with $\mathrm{HHC}$ rates via email and shared them with staff at morning handover meetings. In a second phase teams were asked to set HHC goals and colleagues were encouraged to prompt each other.

$\begin{array}{ll}\text { Birnbach et } & \text { Improve HHC among medical } \\ a l^{25} & \text { students and graduates. }\end{array}$

Trainees were randomly assigned so that some encountered a fresh-smelling environment and others a standard setting.

Iversen et Improve HHC among surgical HCPs. An automated monitoring system measured $a^{26}$ $\mathrm{HHC}$ and alcohol-based hand rubbing events. Sensors on dispensers and datadriven performance feedback highlighted $\mathrm{HHC}$ of HCPs individually and compared with colleagues.

Kim et $a^{27} \quad$ Improve patient influenza vaccination Active choice was implemented in the rates. EHR prompting medical assistants to ask patients about vaccination during check-in and template orders for clinicians to review.

$\begin{array}{ll}\text { Patel et } \text { al }^{28} & \begin{array}{l}\text { Improve patient influenza vaccination } \\ \text { rates. }\end{array} \\ \begin{array}{ll}\text { Lehmann et } & \begin{array}{l}\text { Improve HCP influenza vaccination } \\ \text { rates. }\end{array}\end{array}\end{array}$

EHR confirmed patient eligibility during clinic visit and prompted the physician and medical assistant to actively choose to 'accept' or 'cancel' a vaccination order.

HCPs were randomly assigned to either an opt-out condition to a pre-scheduled appointment for vaccination (could be changed or cancelled) or an opt-in condition where they had to schedule an appointment if they wanted to get vaccinated. Only opt-out participants were sent a reminder. dispensers increased use of hand rub.

$\mathrm{HHC}$ was improved with the clean, citrus smell and also when a picture of 'male eyes' was placed over the hand gel dispenser.

$\mathrm{HHC}$ was improved among those who described themselves as a socially cohesive team.

The fresh scent group had a higher rate of $\mathrm{HHC}$.

Doctors and nurses increased HHC. Nurses who also received feedback increased $\mathrm{HHC}$ even more.

Vaccination rates increased compared with pre-intervention period.

Vaccination rates increased compared with the pre-intervention period.

HCPs in the opt-out condition were more likely to have an appointment for influenza vaccination, which in turn increased the probability of getting vaccinated.
Posters displayed next to 
Table 1 Continued

\begin{tabular}{|c|c|c|c|}
\hline Reference & Nudging objective and target & Implementation details & Findings \\
\hline $\begin{array}{l}\text { Schmidtke et } \\
a l^{30}\end{array}$ & $\begin{array}{l}\text { Improve HCP influenza vaccination } \\
\text { rates. }\end{array}$ & $\begin{array}{l}\text { HCPs received one of four reminder letters: } \\
\text { a standard letter encouraging the staff to } \\
\text { take up the vaccination, a second letter } \\
\text { using peer comparisons, a third letter } \\
\text { with an appeal to authority, a fourth letter } \\
\text { included a combination. }\end{array}$ & $\begin{array}{l}\text { Vaccination coverage in all groups } \\
\text { was the same. No evidence was } \\
\text { found that the uptake of the } \\
\text { seasonal influenza vaccination was } \\
\text { affected by reminders using social } \\
\text { norms to motivate uptake. }\end{array}$ \\
\hline Lorini et $a l^{31}$ & $\begin{array}{l}\text { Increase staff vaccination at nursing } \\
\text { homes. }\end{array}$ & $\begin{array}{l}\text { A personal letter, signed by a high-profile } \\
\text { person, was sent to raise awareness on the } \\
\text { professional responsibility of vaccination } \\
\text { together with a delivering form, a } \\
\text { questionnaire on vaccination intent and an } \\
\text { information leaflet. }\end{array}$ & $\begin{array}{l}\text { Both vaccination uptake and } \\
\text { vaccination intent increased. }\end{array}$ \\
\hline
\end{tabular}

$\begin{array}{ll}\text { Changolkar Improve HCP influenza vaccination } \\ \text { et }\left.a\right|^{32} & \text { rates. }\end{array}$

Meeker et $a l^{33}$ Encourage HCP to judicious use of antibiotics for ARIs.
The EHR assessed patient eligibility for vaccination and prompted medical assistants to accept or cancel an order for the vaccine. If accepted, the order was templated for the HCP to review and sign during patient visit.

Commitment letters with HCP photographs and signatures were displayed in examination rooms stating their commitment to avoid inappropriate

antibiotic prescribing.

$\begin{array}{ll}\text { Meeker et } a l^{34} & \text { Reduce HCP inappropriate antibiotic } \\ \text { prescribing. }\end{array}$
prescribing.

\section{Influenza vaccination rates} increased.

$\begin{array}{llll}\begin{array}{l}\text { Tannenbaum } \\ \text { et } a^{36}\end{array} & \begin{array}{l}\text { Improve HCP guideline concordance } \\ \text { for ARIs. }\end{array} & \begin{array}{l}\text { HCPs randomly assigned to simulated EHR A reduction in choosing aggressive } \\ \text { displays listing antibiotics individually or } \\ \text { grouping them together. }\end{array} & \begin{array}{l}\text { aptions were grouped compared } \\ \text { treatment options when aggressive } \\ \text { with when listed individually. }\end{array} \\ \begin{array}{llll}\text { Dos Santos } \\ \text { et }\left.a\right|^{37}\end{array} & \begin{array}{l}\text { Improve HCP dosing for } \\ \text { antimicrobials. }\end{array} & \begin{array}{l}\text { A window was inserted in the EHR with } \\ \text { measurements of patient's renal function } \\ \text { instead of demanding actively clicking. }\end{array} & \begin{array}{l}\text { The approach increased } \\ \text { appropriateness of dosing. }\end{array}\end{array}$

$\mathrm{ARI}$, acute respiratory infection; EHR, electronic health record; HCPs, healthcare professionals; HHC, hand hygiene compliance; ICU, intensive care unit; LPV, lung-protective ventilation; TVe, tidal volume.

each other to wash their hands-could improve hand hygiene.

\section{Increasing vaccination rates for staff and patients}

Four of the six studies had significant positive results. Three studies focused on increasing vaccination orders for patients, and three focused on that of the HCPs. All patient-oriented studies used active choice strategies, automatically prompting providers via EHRs to accept or decline vaccination orders to eligible patients. ${ }^{272832}$ These strategies impact HCPs with a higher workload more than those with a low workload. ${ }^{32}$
The HCP-focused interventions used letters and emails to HCPs, reminding them to get vaccinated. One study focused on creating messages based on social norms to encourage vaccination. ${ }^{30}$ Another study compared strategies using pre-scheduled vaccination appointments (opt-out) versus reminders to schedule vaccination appointments (opt-in). ${ }^{29}$ However, neither showed statistically significant differences.

Lorini $e t a l^{31}$ also sent personal letters to nursing home staff, signed by high-profile persons (the Chief Director of the Health Regional Agency and the Head of the Department of Health Sciences), to raise awareness not 


\section{active}

\section{synchronous}

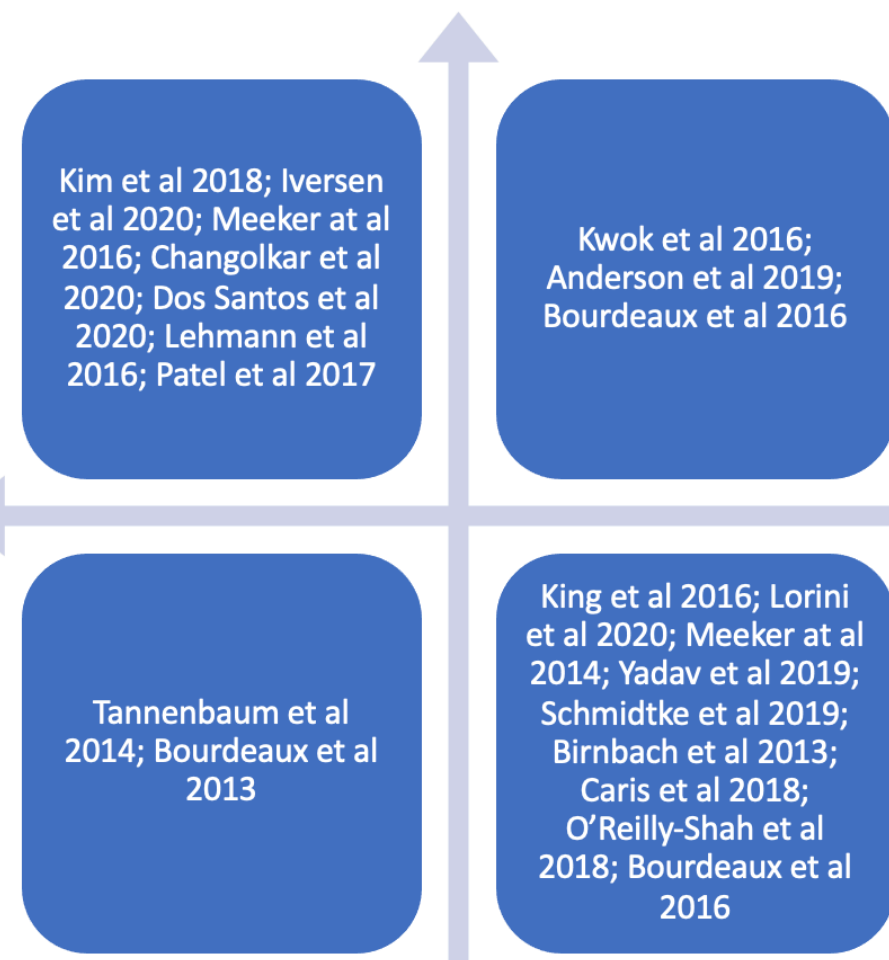

\section{passive}

Figure 2 How included studies fit into a two-dimensional view of nudging.

only about their professional responsibility but also the personal working burden the staff would have to deal with in cases of colleagues getting sick. Unlike Schmidtke et $a l,{ }^{30}$ Lorini $e t a l^{31}$ found a significant effect in the intervention group regarding the intention to get the influenza vaccine, which increased from 2018 to 2019 and 2020.

\section{Judicious antibiotic prescription}

All five studies had a significant positive outcome. Postersized commitment letters were displayed in examination rooms, reminding clinicians of their pledge to judicious antibiotic prescription and informing patients of the importance of that choice. ${ }^{33} 35$ They showed that simply eliciting the intent to perform an action increases the chances of performing it. ${ }^{3}$ It is noteworthy that posters as visual cues are a passive and asynchronous strategy; but these were personalised, showing photos and names of clinicians who had pledged.

Two studies ${ }^{345}$ sent private emails to HCPs with performance metrics, comparing individuals with their groups and top-performing peers. Peer comparison relies on social norms and is an effective nudging strategy. ${ }^{38}$

In one study, ${ }^{34}$ clinicians were presented with suggestions for non-antibiotic treatment together with the message "Antibiotics are not recommended for this diagnosis. See the alternatives below'. If clinicians decided to continue with the antibiotic prescription, they were required to enter a free-text justification for their choice in the EHRs prescription ordering system. This is an active and synchronous strategy that not only requires immediate action but also forces the clinician to reason about their choice.

Tannenbaum et $a l^{36}$ nudged appropriate prescription by rearranging the visual display of treatment options in the EHRs. HCPs showed a $11.5 \%$ reduction in choosing aggressive treatment options (eg, broad-spectrum antibiotics) when these were shown in groups compared with individual lists. This passive and subconscious effect may be explained by 'anchoring' - treatments are perceived as more aggressive when grouped with other aggressive treatments; or 'priming' - the perception of certain treatments is subconsciously affected by seeing other treatment options listed closely.

To increase the appropriateness of dosing based on renal function, Dos Santos $e t a l^{37}$ made a simple change in the EHRs layout to show the patients' latest estimated glomerular filtration rate on the main screen. Before the intervention, this information had to be accessed by actively clicking (four clicks) on the system-a task that required approximately $15-20 \mathrm{~s}$. This simple change 
increased the appropriateness of dosing from 33.9\% to $41.4 \%$. Both these studies ${ }^{36}$ suggest that order sets should not be arbitrary.

\section{DISCUSSION}

We identified and described how nudging techniques have been used to affect the behaviour of HCPs in ways that are relevant for handling the COVID-19 pandemic in a clinical setting. Four focus areas were found that could be implemented quite easily: mechanical ventilation, hand hygiene, vaccination and antibiotic prescription.

\section{Nudging care of ventilated patients}

The COVID-19 pandemic has put severe strain on available ICU beds, with a large number of patients requiring invasive mechanical ventilation (MV) for COVID-19associated pneumonia and acute respiratory distress syndrome (ARDS).$^{39}$ These patients account for a substantial portion of ICU admissions and hospital costs. ${ }^{40}$ In addition to the risks intrinsic to MV, ventilator-associated pneumonia (VAP) has been reported as a complication in hospitalised patients with COVID-19. ${ }^{41-43}$

Our review indicates that default strategies may improve outcomes in MV patients. It has been shown that although low TVe ventilation benefits MV patients with ARDS, ${ }^{44}$ there is poor compliance. ${ }^{45}$ Additionally, the preventive use of chlorhexidine mouthwash can reduce (VAP). Default settings for ventilators coupled with alarms can improve compliance with low TVe ventilation. Furthermore, the default inclusion of chlorhexidine mouthwash on order sets for intubated patients significantly increases its preventive use, thus improving patient outcomes. Default strategies that reduce the cognitive burden on HCPs nudge them to better comply with clinical evidence.

\section{Nudging hand hygiene}

The COVID-19 pandemic has resulted in worldwide hand hygiene awareness. Unfortunately, studies have shown that hand hygiene is often inadequately practised among HCPs ${ }^{46-48}$ despite studies showing that it may decrease the spread of transmissible disease by $24 \%-31 \%,{ }^{49} 50$ and is considered one of the most important measures to prevent hospital-acquired infections. ${ }^{51-53}$

Our review shows that priming strategies that alter the physical environment with images, messages and fragrances can improve hand hygiene compliance (HHC). These are easy and cost-effective interventions that can increase safety in the clinical setting and prevent the spread of COVID-19 in the short term. Visual and olfactory nudges can work as subconscious cues to action but can also easily be ignored. The long-term effects of such strategies were not discussed in the studies we reviewed; more complex strategies may be needed to affect hand washing behaviour in the long term.

\section{Nudging vaccination}

Vaccination is a core component in mitigating the COVID-19 pandemic. $^{54}$ However, the efficacy of vaccination programmes largely depends on population compliance and vaccine hesitancy or refusal around COVID-19 vaccines quickly became a growing concern in most countries. The fraction of the population that must be vaccinated against COVID-19 to achieve herd immunity has been estimated to be $60 \%-80 \% .{ }^{55}$ Although there is precedence for mandatory vaccination programmes around the world ${ }^{56}$ and current discussions regarding COVID-19 vaccines, ${ }^{57}$ it is likely that vaccination will remain an individual choice.

Despite numerous campaigns and initiatives, voluntary influenza vaccination rates in the USA have remained mostly unchanged for nearly a decade, with only $40 \%$ of the population being vaccinated each year. ${ }^{58}$ Recent studies have shown that staff vaccination rates in nursing homes are generally low. ${ }^{59} 60$ Since nursing homes and other long-term care facilities account for a disproportionate share of COVID-19 cases and fatalities worldwide, increasing vaccination rates among nursing home staff is especially important. Vaccines have been especially instrumental in reducing COVID-19 cases and related deaths among nursing home residents, ${ }^{61}$ but at the same time vaccine hesitancy or refusal around COVID-19 vaccines is a growing concern worldwide and has become an issue in most countries.

Therefore, public awareness campaigns and nudging strategies may be key to achieving high vaccination rates. ${ }^{62}$ This review identified two types of interventions: those targeting vaccination orders for patients and those targeting staff vaccination. While all the patient-focused interventions had a positive result, two out of three interventions directed at HCPs did not. It is noteworthy that these passive and asynchronous strategies could easily be ignored, whereas the patient-oriented strategies were active and synchronous, requiring immediate action, which could prove valuable during a mass vaccination campaign. That said, HCPs might now have a much different emotional and cognitive response to COVID-19 than influenza, and new intervention strategies should be investigated. The significant positive results found by Lorini $e t a l^{31}$ could for instance be due to the already large impact of COVID-19 affecting inclination towards vaccination among HCPs. Other studies have shown vaccine hesitancy among skilled nursing facility staff regarding the COVID-19 vaccine, either because of the development and testing or personal fears of getting sick. ${ }^{63}$ An effective behaviour change strategy for COVID-19 vaccines uptake will therefore need to address multiple beliefs and behavioural determinants, by reducing barriers and leveraging enablers. ${ }^{64}$ Text-based reminders have for instance been shown to be effective to get patients vaccinated, especially when designed to make them feel ownership of the vaccine dose ${ }^{6566}$ and that the vaccine dose was reserved for them. ${ }^{65}$ This has also been tested on actual uptake of COVID-19 vaccines. ${ }^{66}$ This is something future nudging studies need to explore when it comes to HCPs. 


\section{Nudging antibiotic prescriptions}

Appropriate hospital antibiotic use is a key element in patient safety, and it has been shown that antibiotics are often unnecessary in the treatment of COVID-19. ${ }^{67}$ Although bacterial co-pathogens are common in viral respiratory infections, the prevalence of bacterial infections in patients with COVID-19 is not well understood. ${ }^{68}$ Hence, the prevention of inappropriate antibiotic use is important not only to reduce the risk of opportunistic infections and other adverse drug events, but also to deter the natural selection of antibiotic-resistant bacteria. ${ }^{69} 70$

Our review indicates that social interventions such as public pledges, public-facing commitment letters and peer comparisons can effectively reduce inappropriate antibiotic prescriptions. EHRs or electronic prescription systems are important tools for changing prescribing behaviour. Both passive and active strategies have shown promise for reducing inappropriate antibiotic prescriptions. Health providers should not only consider how medications are displayed, but also the steps required to complete an order as possible windows of opportunities to deliver nudging interventions via the EHR.

\section{Using the two-dimensional view of nudging}

The active/passive and synchronous/asynchronous dimensions are practical in characterising how and when HCPs are exposed to the nudging intervention, without requiring deep knowledge of behavioural economics or behavioural psychology.

These two dimensions created four quadrants, each containing different nudging strategies (figure 3). While active strategies enable the clinician to consciously reflect on the target behaviour, passive strategies can reduce their cognitive burden by making a behaviour easier or automatic.

\section{CONCLUSION}

Evidence suggests that different nudging techniques can be used in clinical settings as simple, cost-effective strategies to fight COVID-19, reduce complications for intubated patients, improve hand hygiene, increase vaccination rates and avoid unnecessary antibiotic prescriptions. These strategies could be important in the continued handling of the pandemic, which will not be over until the whole world reaches herd immunity from vaccination.

\section{active}

\section{synchronous}
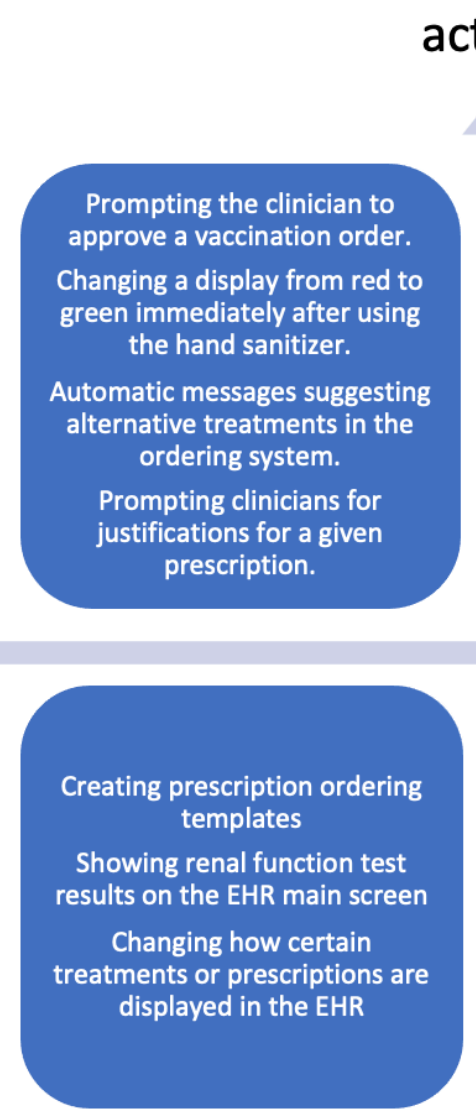

asynchronous

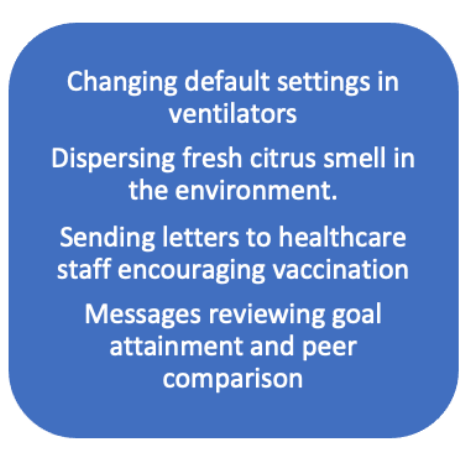


As the COVID-19 pandemic continues, there is a need to gather the best available evidence-based treatment to avoid death and unnecessary suffering. The first wave led to better treatment options during the second and third wave. ${ }^{71}$ Nudging techniques can be an easy and costeffective way to optimise care and, ultimately, save lives. Twitter Andreas Vilhelmsson @andvilhelm

Acknowledgements The authors would like to thank Editage (www.editage.com) for English language editing.

Contributors AV and AS contributed equally to the extraction of data, analysis, writing and reviewing of this manuscript. AW contributed to writing and reviewing this manuscript.

Funding The study was funded by the Centre for Person-Centred Care (GPCC). GPCC is funded by the Swedish Government's grant for Strategic Research Areas, Care Sciences (Application to Swedish Research Council No. 2009-1088) and co-founded by the University of Gothenburg.

Competing interests None declared.

Patient consent for publication Not required.

Ethics approval This study does not involve human participants.

Provenance and peer review Not commissioned; externally peer reviewed.

Data availability statement All data relevant to the study are included in the article or uploaded as supplementary information. The dataset used in this study is available here: https://doi.org/10.5281/zenodo.5545926

Supplemental material This content has been supplied by the author(s). It has not been vetted by BMJ Publishing Group Limited (BMJ) and may not have been peer-reviewed. Any opinions or recommendations discussed are solely those of the author(s) and are not endorsed by BMJ. BMJ disclaims all liability and responsibility arising from any reliance placed on the content. Where the content includes any translated material, BMJ does not warrant the accuracy and reliability of the translations (including but not limited to local regulations, clinical guidelines, terminology, drug names and drug dosages), and is not responsible for any error and/or omissions arising from translation and adaptation or otherwise.

Open access This is an open access article distributed in accordance with the Creative Commons Attribution Non Commercial (CC BY-NC 4.0) license, which permits others to distribute, remix, adapt, build upon this work non-commercially, and license their derivative works on different terms, provided the original work is properly cited, appropriate credit is given, any changes made indicated, and the use is non-commercial. See: http://creativecommons.org/licenses/by-nc/4.0/.

ORCID iD

Andreas Vilhelmsson http://orcid.org/0000-0002-6635-8182

\section{REFERENCES}

1 Starcke K, Brand M. Decision making under stress: a selective review. Neurosci Biobehav Rev 2012;36:1228-48.

2 Keinan G. Decision making under stress: scanning of alternatives under controllable and uncontrollable threats. J Pers Soc Psychol 1987;52:639-44

3 Thaler RH, Sunstein CR. Nudge: improving decisions about health, wealth, and happiness. New Haven and London: Yale University Press, 2008.

4 Sunstein CR. Nudging: a very short guide. J Consum Policy 2014;37:583-8.

5 Bucher T, Collins C, Rollo ME, et al. Nudging consumers towards healthier choices: a systematic review of positional influences on food choice. Br J Nutr 2016;115:2252-63.

6 Wilson AL, Buckley E, Buckley JD, et al. Nudging healthier food and beverage choices through salience and priming. Evidence from a systematic review. Food Qual Prefer 2016;51:47-64.

7 Tørris $\mathrm{C}$, Mobekk $\mathrm{H}$. Improving cardiovascular health through nudging healthier food choices: a systematic review. Nutrients 2019;11:2520.

8 Cohen IG, Fernandez Lynch H, Robertson CT, eds. Nudging health: health law and behavioral economics. Baltimore, Maryland: Johns Hopkins University Press, 2016.

9 Sunstein CR. Nudging smokers. N Engl J Med 2015;372:2150-1.
10 Ledderer L, Kjær M, Madsen EK, et al. Nudging in public health lifestyle interventions: a systematic literature review and metasynthesis. Health Educ Behav 2020;47:749-64.

11 Forberger S, Reisch L, Kampfmann T, et al. Nudging to move: a scoping review of the use of choice architecture interventions to promote physical activity in the general population. Int J Behav Nutr Phys Act 2019;16:77.

12 Patel MS, Volpp KG, Asch DA. Nudge units to improve the delivery of health care. N Engl J Med 2018;378:214-6.

13 Vallgårda S. Nudge: a new and better way to improve health? Health Policy 2012;104:200-3.

14 Yoong SL, Hall A, Stacey F, et al. Nudge strategies to improve healthcare providers' implementation of evidence-based guidelines, policies and practices: a systematic review of trials included within Cochrane systematic reviews. Implement Sci 2020;15:50.

15 Birch K, Chiappetta M, Artyushina A. The problem of innovation in technoscientific capitalism: data rentiership and the policy implications of turning personal digital data into a private asset. Policy Studies 2020;41:468-87.

16 Ouzzani M, Hammady H, Fedorowicz Z, et al. Rayyan-a web and mobile APP for systematic reviews. Syst Rev 2016;5:210.

17 Thinking KD. Fast and slow. New York: Farrar, Straus and Giroux, 2011.

18 Bourdeaux CP, Davies KJ, Thomas MJC, et al. Using 'nudge' principles for order set design: a before and after evaluation of an electronic prescribing template in critical care. BMJ Qual Saf 2014;23:382-8.

19 Bourdeaux CP, Thomas MJ, Gould TH, et al. Increasing compliance with low tidal volume ventilation in the ICU with two nudge-based interventions: evaluation through intervention time-series analyses. BMJ Open 2016;6:e010129.

20 O'Reilly-Shah VN, Easton GS, Jabaley CS, et al. Variable effectiveness of stepwise implementation of nudge-type interventions to improve provider compliance with intraoperative low tidal volume ventilation. BMJ Qual Saf 2018;27:1008-18.

21 Anderson BJ, Do D, Chivers C, et al. Clinical impact of an electronic dashboard and alert system for sedation minimization and ventilator liberation: a before-after study. Crit Care Explor 2019;1:e0057.

22 Caris MG, Labuschagne HA, Dekker M, et al. Nudging to improve hand hygiene. J Hosp Infect 2018;98:352-8.

23 King D, Vlaev I, Everett-Thomas R, et al. "Priming" hand hygiene compliance in clinical environments. Health Psychol 2016;35:96-101.

24 Kwok YLA, Harris P, McLaws M-L. Social cohesion: the missing factor required for a successful hand hygiene program. Am J Infect Control 2017;45:222-7.

25 Birnbach DJ, King D, Vlaev I, et al. Impact of environmental olfactory cues on hand hygiene behaviour in a simulated hospital environment: a randomized study. J Hosp Infect 2013;85:79-81.

26 Iversen A-M, Stangerup M, From-Hansen M, et al. Light-guided nudging and data-driven performance feedback improve hand hygiene compliance among nurses and doctors. Am J Infect Control 2021;49:30991-3.

$27 \mathrm{Kim}$ RH, Day SC, Small DS, et al. Variations in influenza vaccination by clinic appointment time and an active choice intervention in the electronic health record to increase influenza vaccination. JAMA Netw Open 2018;1:e181770.

28 Patel MS, Volpp KG, Small DS, et al. Using active choice within the electronic health record to increase influenza vaccination rates. $J$ Gen Intern Med 2017;32:790-5.

29 Lehmann BA, Chapman GB, Franssen FME, et al. Changing the default to promote influenza vaccination among health care workers. Vaccine 2016;34:1389-92.

30 Schmidtke KA, Nightingale PG, Reeves K, et al. Randomised controlled trial of a theory-based intervention to prompt front-line staff to take up the seasonal influenza vaccine. BMJ Qual Saf 2020;29:189-97.

31 Lorini C, lerardi F, Gatteschi C, et al. Promoting influenza vaccination among staff of nursing homes according to behavioral insights: analyzing the choice architecture during a nudge-based intervention. Vaccines 2020;8:600.

32 Changolkar S, Rewley J, Balachandran M, et al. Phenotyping physician practice patterns and associations with response to a nudge in the electronic health record for influenza vaccination: a quasi-experimental study. PLoS One 2020;15:e0232895.

33 Meeker D, Knight TK, Friedberg MW, et al. Nudging guidelineconcordant antibiotic prescribing: a randomized clinical trial. JAMA Intern Med 2014;174:425-31.

34 Meeker D, Linder JA, Fox CR, et al. Effect of behavioral interventions on inappropriate antibiotic prescribing among primary care practices: a randomized clinical trial. JAMA 2016;315:562-70. 
35 Yadav K, Meeker D, Mistry RD, et al. A multifaceted intervention improves prescribing for acute respiratory infection for adults and children in emergency department and urgent care settings. Acad Emerg Med 2019;26:719-31.

36 Tannenbaum D, Doctor JN, Persell SD, et al. Nudging physician prescription decisions by partitioning the order set: results of a vignette-based study. J Gen Intern Med 2015;30:298-304.

37 Dos Santos RP, Deutschendorf C, Vido HG, et al. Antimicrobial stewardship: the influence of behavioral nudging on renal-functionbased appropriateness of dosing. Infect Control Hosp Epidemiol 2020;41:1077-9.

38 Furth-Matzkin M, Sunstein CR. Social influences on policy preferences: conformity and reactance. Minnesota Law Review 2018;104:1339-79.

39 Papazian L, Klompas M, Luyt C-E. Ventilator-Associated pneumonia in adults: a narrative review. Intensive Care Med 2020;46:888-906.

40 Wunsch H, Linde-Zwirble WT, Angus DC, et al. The epidemiology of mechanical ventilation use in the United States. Crit Care Med 2010;38:1947-53.

41 Yang X, Yu Y, Xu J, et al. Clinical course and outcomes of critically ill patients with SARS-CoV-2 pneumonia in Wuhan, China: a singlecentered, retrospective, observational study. Lancet Respir Med 2020;8:475-81.

42 François B, Laterre P-F, Luyt C-E, et al. The challenge of ventilatorassociated pneumonia diagnosis in COVID-19 patients. Crit Care 2020;24:289

43 Luyt C-E, Sahnoun T, Gautier M, et al. Ventilator-Associated pneumonia in patients with SARS-CoV-2-associated acute respiratory distress syndrome requiring ECMO: a retrospective cohort study. Ann Intensive Care 2020;10:158.

44 Petrucci N, De Feo C. Lung protective ventilation strategy for the acute respiratory distress syndrome. Cochrane Database Syst Rev 2013;2:CD003844.

45 Needham DM, Colantuoni E, Mendez-Tellez PA, et al. Lung protective mechanical ventilation and two year survival in patients with acute lung injury: prospective cohort study. BMJ 2012;344:e2124.

46 Shobowale EO, Adegunle B, Onyedibe K. An assessment of hand hygiene practices of healthcare workers of a semi-urban teaching hospital using the five moments of hand hygiene. Niger Med $J$ 2016;57:150-4.

47 Chavali S, Menon V, Shukla U. Hand hygiene compliance among healthcare workers in an accredited tertiary care hospital. Indian J Crit Care Med 2014;18:689-93.

48 Musu M, Lai A, Mereu NM. Assessing hand hygiene compliance among healthcare workers in six intensive care units. J Prev Med Hyg 2017;58:E231-7.

49 Kantor J. Behavioral considerations and impact on personal protective equipment use: early lessons from the coronavirus (COVID-19) pandemic. J Am Acad Dermatol 2020;82:1087-8.

50 Sickbert-Bennett EE, DiBiase LM, Willis TMS, et al. Reduction of healthcare-associated infections by exceeding high compliance with hand hygiene practices. Emerg Infect Dis 2016;22:1628-30.

51 Pittet D. Compliance with hand disinfection and its impact on hospital-acquired infections. J Hosp Infect 2001;48 Suppl A:540-6.
52 Larson E. A causal link between handwashing and risk of infection? examination of the evidence. Infect Control Hosp Epidemiol 1988;9:28-36.

53 Teare L, Cookson B, French G. Hand washing. A modest measurewith big effects. BMJ 1999;318:686.

54 Hajj Hussein I, Chams N, Chams S, et al. Vaccines through centuries: major cornerstones of global health. Front Public Health 2015;3:269.

55 Wang W, Wu Q, Yang J, et al. Global, regional, and national estimates of target population sizes for covid-19 vaccination: descriptive study. BMJ 2020;371:m4704.

56 Gravagna K, Becker A, Valeris-Chacin R, et al. Global assessment of national mandatory vaccination policies and consequences of noncompliance. Vaccine 2020;38:7865-73.

57 Gostin LO, Salmon DA, Larson HJ. Mandating COVID-19 vaccines. JAMA 2021;325:532-3.

58 CDC. Influenza vaccination coverage. Available: https://www.cdc. gov/flu/fluvaxview/index.htm [Accessed 31 Dec 2020].

59 Daugherty JD, Blake SC, Grosholz JM, et al. Influenza vaccination rates and beliefs about vaccination among nursing home employees. Am J Infect Control 2015;43:100-6.

60 Borgey F, Henry L, Lebeltel J, et al. Effectiveness of an intervention campaign on influenza vaccination of professionals in nursing homes: a cluster-randomized controlled trial. Vaccine 2019:37:1260-5.

61 White EM, Yang X, Blackman C, et al. Incident SARS-CoV-2 infection among mRNA-vaccinated and unvaccinated nursing home residents. N Engl J Med 2021;385:474-6.

62 Volpp KG, Loewenstein G, Buttenheim AM. Behaviorally informed strategies for a national COVID-19 vaccine promotion program. JAMA 2021:325:125-6.

63 Harrison J, Berry S, Mor V, et al. "Somebody Like Me": Understanding COVID-19 Vaccine Hesitancy among Staff in Skilled Nursing Facilities. J Am Med Dir Assoc 2021;22:1133-7.

64 Kalam MA, Davis TP, Shano S, et al. Exploring the behavioral determinants of COVID-19 vaccine acceptance among an urban population in Bangladesh: implications for behavior change interventions. PLoS One 2021;16:e0256496.

65 Milkman KL, Patel MS, Gandhi L, et al. A megastudy of textbased nudges encouraging patients to get vaccinated at an upcoming doctor's appointment. Proc Natl Acad Sci U S A 2021;118:e2101165118.

66 Dai H, Saccardo S, Han MA, et al. Behavioural nudges increase COVID-19 vaccinations. Nature 2021:597:404-9.

67 Rawson TM, Moore LSP, Zhu N, et al. Bacterial and fungal coinfection in individuals with coronavirus: a rapid review to support COVID-19 antimicrobial prescribing. Clin Infect Dis 2020;71:2459-68.

68 Langford BJ, So M, Raybardhan S, et al. Bacterial co-infection and secondary infection in patients with COVID-19: a living rapid review and meta-analysis. Clin Microbiol Infect 2020;26:1622-9.

69 CDC. Antibiotic resistance threats in the United States, 2019. Atlanta, GA: U.S. Department of Health and Human Services, CDC 2019.

70 WHO. Global action plan on antimicrobial resistance. Geneva: World Health Organization, 2015.

71 Graichen $\mathrm{H}$. What is the difference between the first and the second/third wave of Covid-19? - German perspective. J Orthop 2021;24:A1-3. 